\title{
PENGEMBANGAN MULTIMEDIA INTERAKTIF CERIA (MIC) PEMBELAJARAN TEMATIK DI SEKOLAH DASAR
}

\author{
Ikhtiari Septiya Hernaningtyas, Roro Eko Susetyarini, Rohmad Widodo \\ Sekolah Dasar Negeri Kedungjati II Kecamatan Kabuh Kabupaten Jombang \\ Email : ikhtiariseptiyahernaningtyas@gmail.com
}

\begin{abstract}
This research purpose are producing interactive multimedia product with validity level as media criteria expected in "My Family" theme in family subject for grade 1 Elementary School. The research uses Research and Development from Borg and Gall with three phases: (a) Introduction Study by doing need assessment and literature study, (b) early product development, expert validation, limited test, and (c) Testing by doing experiment research from hypothetic product to grade 2 Elementary School samples with real class condition in learning. Research shows that multimedia developed can be categorized as worth according to expert validation, according to material expert with total percentage $95 \%$ with very good qualification. Media expert with total percentage $88 \%$ with very good qualification, limited test result with total percentage $100 \%$ very good qualification. This fun interactive multimedia has been tested its validity and effectiveness in class learning. It can be described from pretest 67 and post test 87 . From t test by using paired samples t-test procedure found significant $\mathrm{t}<0.01$ or $1 \%$. According to research result, it can be concluded that fun interactive media development for thematic learning in Elementary School is worth and very useful also can be applied in thematic learning at grade I of elementary school. According to research result, it is suggested that all grade I Elementary School uses learning media, especially fun interactive media. So it will enliven the class atmosphere which will create more concrete material delivery and students' motivation can be increased rapidly, also raising students' creativity.
\end{abstract}

\begin{abstract}
Abstrak: Penelitian ini bertujuan menghasilkan produk multimedia interaktif yang memiliki tingkat kevalidan sebagai kriteria media yang diharapkan pada tema keluargaku pokok bahasan tentang keluarga untuk siswa kelas I SD. Penelitian ini menggunakan Penelitian Pengembangan (Research and Development) dari Borg and Gall dengan tiga tahap, (a) Studi pendahuluan dengan melakukan need assement dan studi pustaka, (b) Pengembangan produk awal,' validasi ahli, uji coba terbatas, dan (c) Pengujian dengan melakukan penelitian eksperimen dari produk hipotetik pada sampel 2 SD dengan kondisi kelas yang sebenarnya dalam pembelajaran. Hasil penelitian menunjukkan bahwa multimedia yang dikembangkan dikategorikan layak berdasarkan validasi ahli menurut ahli materi dengan persentase total 95\% dengan kualifikasi sangat baik, ahli media dengan persentase total $88 \%$ dengan kualifikasi sangat baik, hasil uji coba terbatas dengan persentase total $100 \%$ kualifikasi sangat baik. Multimedia interaktif ceria ini telah teruji kevalidan dan keefektifannya pada pembelajaran di kelas, tergambar dari nilai pretest 67 dan dari posttest 87. Dari uji t dengan menggunakan prosedur paired samples t-test diperoleh nilai $\mathrm{t}$ signifikan $<0.01$ atau $1 \%$. Berdasarkan hasil penelitian dapat disimpulkan bahwa pengembangan multimedia interaktif ceria (MIC) pembelajaran tematik di Sekolah Dasar sangat layak dan memiliki daya guna tinggi serta dapat diterapkan dalam pembelajaran tematik di kelas I SD. Disarankan seharusnya semua kelas I SD menggunakan media pembelajaran, yaitu multimedia interaktif ceria. Sehingga menghidupkan suasana kelas yang akan menciptakan penyampaikan materi lebih konkrit dan motivasi belajar siswa dapat meningkat serta dapat meningkatkan kreativitas siswa.
\end{abstract}

Kata Kunci: pengembangan, MIC, tematik 


\section{PENDAHULUAN}

Undang-Undang RI Nomor 20 Tahun 2003 tentang Sisdiknas menyatakan bahwa pendidikan adalah usaha sadar dan terencana untuk mewujudkan suasana belajar dan proses pembelajaran, agar siswa secara aktif mengembangkan potensi diri untuk memiliki kekuatan spiritual keagamaan, pengendalian diri, kepribadian, kecerdasan, akhlak mulia, serta keterampilan yang diperlukan dirinya, masyarakat, bangsa dan negara.

Salah satu adalah pendidikan dasar, pendidikan dasar merupakan jenjang pendidikan formal untuk siswa mulai usia 7 sampai 12 tahun. Pendidikan dasar merupakan jenjang pendidikan yang melandasi jenjang pendidikan menengah (UU RI Nomor 20 Tahun 2003 tentang Sisdiknas: 6).

Pendidikan dasar merupakan suatu mata pisau tajam yang akan menjadi dasar dalam suatu mata rantai pengetahuan seseorang. Pendidikan dasar berperan dalam pembentukan karakter serta watak siswa agar memiliki kemampuan dalam intelektual maupun spiritual, berilmu pengetahuan yang cerdas, menguasai teknologi dan informasi yang global serta memiliki daya cipta tinggi.

Pendidikan dasar harus memiliki ciri atau profil tumbuh keimanan dan ketaqwaan terhadap Tuhan Yang Maha Esa, tumbuh sikap beretika (sopan santun dan beradab), tumbuh penalaran yang baik (mau belajar, ingin tahu, senang membaca, memiliki inovasi, berinisiatif dan bertanggung jawab), tumbuh kemampuan komunikasi/sosial (tertib, sadar aturan, dapat bekerjasama dengan teman, dapat berkompetisi), dan tumbuh kesadaran untuk menjaga kesehatan badan (Mulyasa, 2013: 21). Hal ini diterapkan dalam suatu kegiatan belajar mengajar yang didasarkan pada sebuah tujuan.
Proses belajar mengajar atau proses pengajaran merupakan suatu kegiatan melaksanakan kurikulum suatu lembaga pendidikan, agar dapat mempengaruhi para siswa mencapai tujuan pendidikan yang telah ditetapkan (Sudjana, 2013: 1). Belajar mengajar dilaksanakan dengan adanya dorongan kedua belah pihak untuk dimajukan dan memajukan serta dicerdaskan dan mencerdaskan. Tanpa adanya kesadaran dan kemauan yang lahir dari hati nurani dan tanpa niat yang kokok, maka kegiatan belajar mengajar tidak akan berjalan sesuai tujuan pendidikan.

Tujuan pendidikan adalah untuk mengembangkan potensi peserta didik agar menjadi manusia yang beriman dan bertakwa kepada Tuhan Yang Maha Esa, berakhlak mulia, sehat, berilmu, cakap, kreatif, mandiri, dan menjadi warga negara yang demokratis serta bertanggung jawab (UU RI Nomor 20 Tahun 2003 tentang Sistem Pendidikan Nasional).

Seiring dengan perkembangan jaman, kemajuan teknologi serta tuntutan masyarakat akan sistem pendidikan nasional yang lebih baik, maka terjadi penyempurnaan pola pikir perumusan kurikulum. Dalam kerangka inilah perlunya pengembangan kurikulum 2013. Pada penjelasan UndangUndang Nomor 20 Tahun 2003 tentang Sistem Pendidikan Nasional di bagian umum dijelaskan bahwa strategi pembangunan pendidikan nasional dalam undangundang ini salah satunya melalui pengembangan dan pelaksanaan kurikulum berbasis kompetensi. Selain itu, pada penjelasan pasal 35 Undang-Undang Sisdiknas ditegaskan bahwa kompetensi lulusan merupakan kualifikasi kemampuan lulusan yang mencakup sikap, pengetahuan, dan keterampilan sesuai dengan standar nasional pendidikan sebagaimana PP Nomor 19 Tahun 2005. Intinya perlunya pegembangan adalah untuk menghadapi berbagai masalah dan tantangan masa depan yang 
semakin lama semakin rumit dan kompleks (Mulyasa, 2013: 63).

Pengembangan kurikulum 2013 telah banyak melahirkan suatu perubahan. Awalnya pembelajaran tematik kurikulum 2006 yang hanya dari kelas I-III, kini pembelajaran tematik intergratif mulai dari kelas I-VI yang dilaksanakan bertahap. Perubahan dan pengembangan kurikulum mulai sekolah dasar (SD), sekolah menengah pertama (SMP), sekolah menengah atas (SMA), sekolah menengah kejuruan (SMK) dilakukan untuk menjawab tantangan zaman yang terus berubah agar siswa mampu bersaing di masa depan, dalam konteks nasional maupun global. Pelaksanaan kurikulum KTSP 2006 hanya tematik untuk kelas I-III (belum integratif) dan kurikulum 2013 tematik integratif untuk kelas I-VI (Mulyasa, 2013: 169). Implementasi kurikulum yang berbasis kompetensi dan karakter ini, siswa SD idealnya tidak lagi banyak menghapal, karena kurikulum ini dirancang untuk mempersiapkan siswa memiliki budi pekerti atau karakter yang baik, sebagai bekal untuk mengikuti pendidikan pada jenjang berikutnya (Mulyasa, 2013: 170). Intinya kurikulum 2013 ini lebih menekankan pada pembelajaran tematik intergratif.

Pembelajaran tematik intergratif pada dasarnya adalah model pembelajaran terpadu yang menggunakan tema untuk mengaitkan beberapa mata pelajaran sehingga dapat memberikan pengalaman bermakna kepada siswa (Trianto (2012: 79). Pembelajaran tematik pada dasarnya memerlukan optimalisasi penggunaan media pembelajaran yang bervariasi sehingga akan membantu siswa dalam memahami konsepkonsep yang abstrak (Trianto, 2012: 128). Pembelajaran tematik akan member kesempatan kepada siswa untuk secara mendalam mengkaji topik-topik yang dikemas secara menarik dan kontekstual (Parwati, 2010: 332). Dalam hal itu, guru mampu menempatkan dirinya dalam keseluruhan proses. Artinya, guru harus mampu menempatkan diri sebagai fasilitator dan mediator dalam pembelajaran. (Trianto, 2012: 85).

Pembelajaran memerlukan proses yang tepat untuk membekali siswa dengan berbagai kompetensi (Mulyasa, 2013: 64). Untuk membekali siswa dalam berbagai kompetensi, perlu menciptakan pembelajaran yang aktif dan bermakna tidak hanya dengan penggunaan metode yang tepat, namun kunci sukses pembelajaran juga ditunjang dengan fasilitas dan sumber belajar. Fasilitas dan sumber belajar harus memadai dan guru harus mampu menciptakan sendiri alat pembelajaran dan media.

Media pembelajaran yang dimaksudkan salah satunya adalah multimedia berbasis komputer. Multimedia berbasis komputer adalah suatu sistem penyampaian dengan menggunakan berbagai jenis bahan belajar yang membentuk suatu unit atau paket. Multimedia memiliki kelebihan yaitu siswa memiliki pengalaman yang beragam dari segala media, dapat menghilangkan kebosanan siswa karena media yang digunakan lebih variasi, dan sangat baik untuk kegiatan belajar mandiri. Namun multimedia juga memiliki kelemahan yaitu biayanya cukup mahal dan perlu perencanaan yang matang dan tenaga yang profesional (Susilana dan Riyana, 2007: 2122).

Multimedia interaktif merupakan alat atau sarana pembelajaran yang materi, metode, batasan-batasan, dan cara mengevaluasi yang dirancang secara sistematis dan menarik untuk mencapai kompetensi/ subkompetensi mata pelajaran yang diharapkan sesuai dengan tingkat kompleksitasnya (Susilana dan Riyana, 2007: 125). Multimedia interaktif sangat memberikan kesan positif pada siswa dalam proses pembelajaran.

Hasil penelitian pengembangan yang dilakukan Suwindra, I Nyoman P, dkk (2009) dalam Jurnal menyimpulkan "respon siswa dan guru tergolong positif, sehingga 
model dapat dikembangkan untuk pokok bahasan yang lain dan mata pelajaran lain". Jurnal lainnya oleh Suwindra (2010) juga membuktikan bahwa "siswa memberikan respon positif terhadap modul, oleh karena itu modul fisika multimedia interaktif layak dan efektif untuk meningkatkan pemahaman konsep dan hasil belajar siswa".

Survey lapangan dan need assessment dengan guru dibeberapa SD yang ada di Jombang pada bulan Januari dan dilanjutkan dengan bulan April 2014 diperoleh hasil bahwa penggunaan metode pembelajaran sudah cukup menarik dan bervariasi. Namun untuk kelengkapan media belum ada. Hanya sekitar 30\% menggunakan media gambar dan lingkungan. Video pembelajaran juga ada namun jarang diberikan. Hasil lain diketahui bahwa anak jika diminta membaca buku pada umumnya sulit, anak tidak bisa konsentrasi secara penuh pada bukunya jika membaca, anak juga masih sulit untuk menulis dan membaca, dan pada saat guru menjelaskan kadang tidak memperhatikan guru secara penuh. Anak masih memiliki jiwa bermain.

Penggunaan media yang belum maksimal dalam pembelajaran tematik dan kondisi siswa di lapangan, sehingga pembelajaran kurang optimal, maka dikembangkan sebuah alat penghubung atau alat komunikasi yaitu multimedia interaktif yang dapat menarik perhatian dan memotivasi siswa. Media berfungsi sebagai alat untuk memperlancar penyampaian materi dan meningkatkan motivasi dan efektivitas hasil belajar siswa. Multimedia interaktif ceria cocok untuk siswa SD karena mereka masih memiliki pola pikir yang konkrit terutama kelas rendah. Multiimedia interaktif ceria ini berisi tentang penjelasan anggota keluarga besar, adab dalam keluarga, sikap saling menghargai dalam keluarga serta operasi hitung penjumlahan pengurangan dalam bentuk cerita yang menarik bagi siswa. Animasi dan suara yang akan membangkitkan motivasi serta semangat untuk tetap mengikuti pembelajaran sampai usai serta warna yang dasar yang cerah dan menarik bagi anak.

Hal tersebut mendorong peneliti ingin mengatasi masalah dengan menciptakan suatu media pembelajaran yang menarik dan menyenangkan bagi siswa, yaitu dengan mengembangkan Multimedia Inteaktif Ceria (MIC) Pembelajaran Tematik di Sekolah Dasar.

Multimedia interaktif ceria adalah multimedia interaktif yang terdapat fiturfitur yang terdiri dari satu-kesatuan antara audio visual mulai dari animasi, suara, video, teks yang menciptakan suasana belajar yang ceria, karena terdapat musik dan juga warna yang cerah.

Tujuan penelitian ini adalah menghasilkan produk multimedia interaktif yang memiliki tingkat kevalidan sebagai kriteria media yang diharapkan pada tema keluarga$\mathrm{ku}$ pokok bahasan tentang keluarga untuk siswa kelas I SD.

\section{METODE PENELITIAN}

Penelitian ini adalah penelitian pengembangan (R\&D). Penelitian pengembangan bertujuan untuk mengembangkan suatu produk atau menciptakan produk baru. Penelitian ini dilaksanakan dengan tiga tahap, yaitu (a) studi pendahuluan dengan melakukan need assement dan studi pustaka, (b) pengembangan produk awal, validasi ahli, uji coba terbatas, dan (c) pengujian dengan melakukan penelitian eksperimen dari produk hipotetik pada sampel 2 SD dengan kondisi kelas yang sebenarnya dalam pembelajaran. Dijabarkan dalam 9 langkah, yaitu (1) penelitian dan pengumpulan data, (2) perencanaan, (3) pengembangan draf produk, (4) uji coba lapangan awal, (5) merevisi hasil uji coba, (6) uji coba lapangan, (7) penyempurnaan produk hasil uji lapangan, (8) uji pelaksanaan lapangan, (9) penyempurnaan produk akhir (Sukmadinata, 2007: 169-170). 
Subjek dalam penelitian adalah ahli materi, ahli media, siswa, dan guru kelas (obsever). Jenis data yang digunakan dalam penelitian ini ada dua yaitu kuantitatif dan kualitatif. Data kuantitatif diperoleh dari penilaian ahli media, ahli materi dan observer melalui angket yang berisi uraian yang masing-masing angka telah memiliki skor terhadap kelayakan multimedia interaktif ceria serta hasil pretest dan posttest siswa. Data kualitatif diperoleh dari hasil wawancara, observasi dan saran, komentar, masukan, kritikan dari ahli media, ahli materi, dan observer terhadap kualitas dan kelayakan multimedia interaktif ceria melalui angket. Data dikumpulkan dengan observasi, wawancara, angket, tes, dan dokumentasi. Data yang terkumpul dianalisis deskriptif kualitatif, statistik deskriptif, dan uji t.

\section{HASIL DAN PEMBAHASAN}

Hasil Need Asessment dan Studi Pustaka. hasil tentang isi materi tema keluargaku yang dikembangkan dalam multimedia interaktif ceria.

\begin{tabular}{|l|l|l|}
\multicolumn{1}{|c|}{ Tabel 4.1 Materi tema keluargaku hasil need } \\
asessment
\end{tabular}

Hasil Perencanaan dan Pengembangan Draf Produk Multimedia Interaktif Ceria (MIC). Materi yang telah dikembangkan melalui need asessment dan studi pustaka, selanjutnya peneliti melakukan rancangan pembuatan media (RPM).

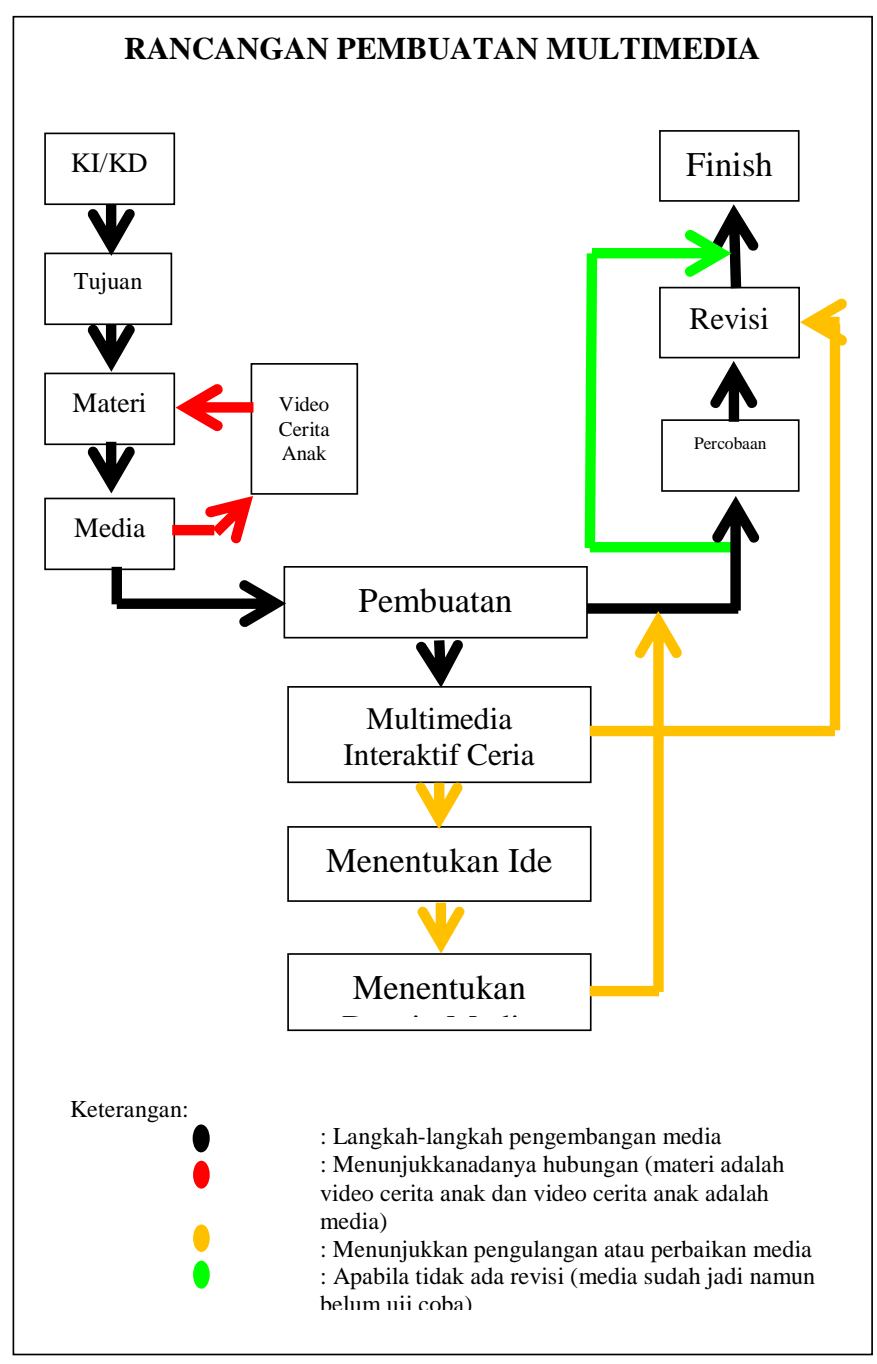

Gambar 4.1 Rancangan pembuatan media

Hasil Pengembangan Materi. Ruang lingkup materi pada multimedia interaktif ceria berdasarkan kompetensi inti dan kompetensi dasar kelas I semester 1 dapat dilihat pada Tabel 4.2.

Tabel 4.2 Ruang lingkup kompetensi inti dan kompetensi dasar

\begin{tabular}{ll}
$\begin{array}{c}\text { Kompetensi Inti } \\
(\text { KI) }\end{array}$ & $\begin{array}{c}\text { Kompetensi Dasar } \\
(\text { KD) }\end{array}$ \\
\hline 4. Menyajikanpen & a. Matematika \\
getahuanfaktual & 4.1. Mengemukakank \\
dalambahasa & embalidengankali \\
yang & matsendiridanme \\
jelasdanlogis, & mecahkanmasala \\
\hline
\end{tabular}




\begin{tabular}{|c|c|}
\hline dalamkarya & yang \\
\hline yang estetis, & berkaitandenganp \\
\hline dalamgerakan & enjumlahandanpe \\
\hline yang & nguranganterkaita \\
\hline mencerminkana & ktivitassehari-hari \\
\hline naksehat, & rumah, \\
\hline dandalamtindak & sekolah, atau di \\
\hline yang & tempatbermainser \\
\hline mencerminkanp & tamemeriksakebe \\
\hline erilakuanakberi & narannya. \\
\hline mandanberakhla & b. Bahasa Indonesia \\
\hline kmulia. & 4.4. Menyampaikante \\
\hline & ksceritadiri/perso \\
\hline & nal \\
\hline & tentangkeluargase \\
\hline & bahasa Indonesia \\
\hline & lisandantulis yang \\
\hline & dapatdiisidengan \\
\hline & kosakatabahasada \\
\hline & $\begin{array}{l}\text { erahuntukmemba } \\
\text { ntupenyaijian. }\end{array}$ \\
\hline
\end{tabular}

Pengembangan multimedia interaktif media ini mengacu pada KI dan KD yang terurai pada Tabel 4.2 dengan indikator yang ingin dicapai pada Tabel 4.3 berikut ini.

Tabel 4.3 Ruang lingkup indikator

\begin{tabular}{|c|c|}
\hline No & Indikator \\
\hline 1 & $\begin{array}{l}\text { Menyebutkan anggota } \\
\text { keluarga besar }\end{array}$ \\
\hline 2 & $\begin{array}{l}\text { Menyebutkan } \\
\text { pengertian dari masing-masing } \\
\text { nama anggota keluarga besar. }\end{array}$ \\
\hline 3 & $\begin{array}{c}\text { Menyebutkan banyak } \\
\text { anggota Keluarga besar Dayu }\end{array}$ \\
\hline 4 & $\begin{array}{c}\text { Menyebutkan sikap } \\
\text { saling berbagi dalam keluarga }\end{array}$ \\
\hline 5 & $\begin{array}{llr} & \text { Menyelesaikan soal } \\
\text { cerita tentang penjumlahan } \\
\text { dan pengurangan sampai } \\
\text { bilangan } 20\end{array}$ \\
\hline 6 & $\begin{array}{r}\text { Menyebutkan adab/hak } \\
\text { dan kewajiban dalam keluarga. }\end{array}$ \\
\hline
\end{tabular}

Hasil validasi multimedia. Hasil validasi multimedia mencakup validasi materi dan validasi media masing-masing dilaporkan sebagai berikut.

Validasi materi dilakukan oleh 1 orang validator. Yang ahli dalam pendidik- an matematika dan sebagai dosen. Validasi materi dalam multimedia dilakukan meliputi 9 aspek dengan rentangan skor untuk masing-masing deskriptor 1 sampai 5 . Dengan 1 sangat kurang baik, 2 kurang baik, 3 cukup baik, 4 baik, dan 5 sangat baik. Hasil validasi ditunjukkan seperti dalam Tabel 4.4.

Validasi media dilakukan oleh 2 orang validator. Yang ahli dalam bidang multimedia dan pembelajaran. Validasi media dilakukan meliputi 16 aspek dengan rentanganskor untuk masing-masing deskriptor adalah 1 sampai 5. Dengan 1 sangat kurang baik, 2 kurang baik, 3 cukup baik, 4 baik, dan 5 sangat baik. Hasil validasi media ditunjukkan seperti Tabel 4.5.

Tabel 4.4 Hasil Validasi Materi Sebelum dan Sesudah Revisi

\begin{tabular}{|c|l|c|c|}
\hline No & \multicolumn{1}{|c|}{$\begin{array}{c}\text { Uraian } \\
\text { Instrumen }\end{array}$} & $\begin{array}{c}\text { Sebelum } \\
\text { Revisi }\end{array}$ & $\begin{array}{c}\text { Sesudah } \\
\text { Revisi }\end{array}$ \\
\cline { 3 - 4 } & $\begin{array}{l}\text { Skor } \\
\text { Penggunaan } \\
\text { teks sangat } \\
\text { jelas dalam } \\
\text { multimedia } \\
\text { interaktif } \\
\text { ceria. }\end{array}$ & 5 & 5 \\
\hline 2 & $\begin{array}{l}\text { Penggunaan } \\
\text { animasi sesuai } \\
\text { cerita }\end{array}$ & 5 & 5 \\
\hline 3 & $\begin{array}{l}\text { Penggunaan } \\
\text { suara jelas } \\
\text { antara dimensi } \\
\text { dancerita }\end{array}$ & 5 & 4 \\
\hline 4 & $\begin{array}{l}\text { Penggunaan } \\
\text { animasi, suara, } \\
\text { video sesuai } \\
\text { konsep materi }\end{array}$ & $\begin{array}{l}\text { Seraian } \\
\text { Uraian materi } \\
\text { lengkap dalam } \\
\text { multimedia } \\
\text { interaktif } \\
\text { ceria. }\end{array}$ & $\begin{array}{l}\text { Uraian materi } \\
\text { sesuai dengan } \\
\text { tujuan } \\
\text { pembelajaran } \\
\text { dalam } \\
\text { multimedia } \\
\text { interaktif } \\
\text { ceria. }\end{array}$ \\
\hline 5 & 4 & 4 \\
\hline
\end{tabular}




\begin{tabular}{|c|l|c|c|}
\hline 7 & $\begin{array}{l}\text { Ketepatan } \\
\text { materi pada } \\
\text { multimedia } \\
\text { interaktif }\end{array}$ & 5 & 5 \\
\hline 8 & $\begin{array}{l}\text { Uraian materi } \\
\text { memberikan } \\
\text { daya tarik } \\
\text { pada siswa } \\
\text { untuk belajar } \\
\text { lebih lama }\end{array}$ & 4 & 5 \\
\hline 9 & $\begin{array}{l}\text { Materi } \\
\text { menarik } \\
\text { perhatian } \\
\text { siswa dalam } \\
\text { multimedia } \\
\text { interaktif ceria }\end{array}$ & 4 & 5 \\
\hline
\end{tabular}

Tabel 4.5 Hasil Validasi Media Sebelum dan Sesudah Revisi

\begin{tabular}{|c|c|c|c|c|c|}
\hline \multirow[b]{2}{*}{ No } & \multirow{2}{*}{$\begin{array}{c}\text { Uraian } \\
\text { Instrumen }\end{array}$} & \multicolumn{2}{|c|}{$\begin{array}{c}\text { Sebelum } \\
\text { Revisi }\end{array}$} & \multicolumn{2}{|c|}{$\begin{array}{c}\text { Sesudah } \\
\text { Revisi }\end{array}$} \\
\hline & & $\begin{array}{c}\text { Vali } \\
\text { dato } \\
\mathbf{r}_{1}\end{array}$ & $\begin{array}{l}\text { Valid } \\
\text { ator }_{2}\end{array}$ & $\begin{array}{c}\text { Vali } \\
\text { dato } \\
\mathbf{r}_{1}\end{array}$ & $\begin{array}{c}\text { Vali } \\
\text { dato } \\
\mathbf{r}_{2} \\
\end{array}$ \\
\hline 1 & $\begin{array}{l}\text { Penggunaan } \\
\text { perangkat } \\
\text { pada materi } \\
\text { sesuai } \\
\text { dengan } \\
\text { tujuan } \\
\text { pembelajara } \\
\text { n }\end{array}$ & 3 & 5 & 4 & 5 \\
\hline 2 & $\begin{array}{l}\text { Media } \\
\text { pembelajara } \\
\text { n sesuai } \\
\text { dengan } \\
\text { indikator } \\
\text { yang } \\
\text { ditentukan }\end{array}$ & 4 & 5 & 5 & 5 \\
\hline 3 & $\begin{array}{l}\text { Tema } \\
\text { keluarga } \\
\text { terfasilitasi } \\
\text { melalui } \\
\text { multimedia } \\
\text { interaktif }\end{array}$ & 3 & 4 & 4 & 5 \\
\hline 4 & $\begin{array}{l}\text { Tingkat } \\
\text { kejelasan } \\
\text { tampilan } \\
\text { visual (teks, } \\
\text { animasi dan } \\
\text { video). }\end{array}$ & 3 & 4 & 4 & 4 \\
\hline 5 & $\begin{array}{l}\text { Penyampaia } \\
\text { n audio } \\
\text { (narasi, } \\
\text { musik dan } \\
\text { efek suara) } \\
\text { pada } \\
\text { multimedia } \\
\text { interaktif }\end{array}$ & 3 & 4 & 4 & 4 \\
\hline 6 & Susunan & 3 & 4 & 4 & 4 \\
\hline
\end{tabular}

\begin{tabular}{|c|c|c|c|c|c|}
\hline & $\begin{array}{l}\text { gambar, } \\
\text { animasi, } \\
\text { teks, warna, } \\
\text { dan efek. }\end{array}$ & & & & \\
\hline 7 & $\begin{array}{l}\text { Tampilan } \\
\text { fitur pada } \\
\text { multimedia } \\
\text { interaktif } \\
\text { menjelaskan } \\
\text { materi } \\
\text { secara jelas. }\end{array}$ & 3 & 3 & 4 & 5 \\
\hline 8 & $\begin{array}{l}\text { Tampilan } \\
\text { dalam } \\
\text { multimedia } \\
\text { interaktif } \\
\text { memberikan } \\
\text { pengetahuan } \\
\text { yang nyata } \\
\text { pada siswa }\end{array}$ & 3 & 5 & 4 & 4 \\
\hline 9 & $\begin{array}{l}\text { Pengoperasi } \\
\text { an/membuk } \\
\text { a } \\
\text { multimedia } \\
\text { interaktif }\end{array}$ & 4 & 3 & 5 & 4 \\
\hline 10 & $\begin{array}{l}\text { Multimedia } \\
\text { interaktif } \\
\text { memberikan } \\
\text { pemahaman } \\
\text { materi pada } \\
\text { siswa }\end{array}$ & 4 & 5 & 4 & 5 \\
\hline 11 & $\begin{array}{l}\text { Tampilan } \\
\text { audiovisual } \\
\text { meningkatk } \\
\text { an } \\
\text { pemahaman } \\
\text { siswa } \\
\text { dengan } \\
\text { cepat pada } \\
\text { siswa. }\end{array}$ & 4 & 5 & 4 & 5 \\
\hline 12 & $\begin{array}{l}\text { Gambar } \\
\text { tersusun } \\
\text { sangat baik } \\
\text { dan sesuai } \\
\text { tahapan }\end{array}$ & 3 & 5 & 4 & 5 \\
\hline 13 & $\begin{array}{l}\text { Multimedia } \\
\text { interaktif } \\
\text { ceria } \\
\text { memberikan } \\
\text { kesan } \\
\text { konkrit pada } \\
\text { siswa } \\
\text { terhadap } \\
\text { materi. }\end{array}$ & 3 & 5 & 5 & 5 \\
\hline 14 & $\begin{array}{l}\text { Tampilan } \\
\text { multimedia } \\
\text { interaktif } \\
\text { ceria } \\
\text { menarik } \\
\text { siswa untuk } \\
\text { belajar }\end{array}$ & 4 & 5 & 4 & 5 \\
\hline 15 & $\begin{array}{l}\text { Tampilan } \\
\text { warna pada } \\
\text { multimedia }\end{array}$ & 4 & 4 & 4 & 4 \\
\hline
\end{tabular}




\begin{tabular}{|c|c|c|c|c|c|}
\hline & $\begin{array}{l}\text { inetraktif } \\
\text { ceria } \\
\text { menarik }\end{array}$ & & & & \\
\hline 16 & $\begin{array}{l}\text { Susunan } \\
\text { audiovisual } \\
\text { (gambar, } \\
\text { animasi, } \\
\text { teks, audio, } \\
\text { video) } \\
\text { memiliki } \\
\text { daya tarik. }\end{array}$ & 4 & 4 & 4 & 5 \\
\hline
\end{tabular}

Berdasarkan hasil validasi dari ahli materi dan ahli media didapatkan komentar dan saran sebagai berikut.

Validasi ahli materi sebelum revisi. Komentar: 1) petunjuk penggunaan media perlu dilengkapi dengan langkah-langkah penggunaan, 2) respon evaluasi setiap nomor diganti diakhir, 3) tata letak evaluasi diperbaiki, masih ada yang acak, dan 4 sesuaikan dengan indikator. Saran: revisi dan lanjutkan. Validasi ahli materi sesudah revisi. Saran: lanjutkan.

Validasi ahli media sebelum revisi. Validator 1, Komentar: 1) font tulisan diperbesar, 2) petunjuk pemanfaatan/penggunaan diperjelas dan dipersingkat, 3) nada tombol lebih kecil suaranya dari animasi, dan 4) evaluasi harus jelas. Saran: diperbaiki lebih baik. Validator 2, komentar: rancangan desain multimedia secara umum sudah baik dari sisi multimedia. hal yang perlu diperhatikan adalah kemudahan untuk menggunakan kontrol materi dan evaluasi sehingga materi pembelajaran dapat disampaikan secara bertahap sesuai dengan indikator. Evaluasi juga dilakukan perkonteks adegan/scene. Saran: tombol penggunaan materi dan evaluasi ditambahkan untuk memberikan kesempatan kepada guru untuk melakukan dialog kepada siswa tentang materi yang sedang ditayangkan dan atau evaluasi yang perlu dilakukan oleh guru untuk mengetahui tingkat pemahaman siswa terhadap materi. Validasi ahli media sesudah revisi. Validator 1, Komentar dan saran tidak ada. Validator 2, Komentar: setelah dilakukan perbaikan, maka perangkat bantu belajar MIC telah memenuhi unsur desain yang menarik dan interaktif untuk digunakan siswa. Saran: dalam pengembangan media belajar menggunakan media interaktif mengkaitkan materi belajar dengan multimedia sehingga keberhasilan dalam penyampaian materinya tergantung pada bagaimana kemasan (unsur desain) dan outcome (unsur materi) dirancang dengan baik sesuai dengan kaidah unsur desain dan unsur pembelajaran.

Media pembelajaran yang dihasilkan dalam penelitian ini adalah multimedia interaktif ceria dan buku pedoman guru. Multimedia yang telah dihasilkan tersebut dinyatakan "valid", "layak", dan memiliki "daya guna tinggi" pada pembelajaran di kelas melalui penyempurnaan setelah dilakukan uji validasi oleh ahli materi dan ahli media. Dalam uji coba ini dapat diketahui kendala-kendala yang dialami siswa dan guru dalam menggunakan multimedia yang dikembangkan tersebut.

Kendala yang dialami pengembang adalah waktu pembuatan yang membutuhkan waktu lama dan biaya pembuatan yang tidak sedikit. Kendala yang dialami siswa adalah sebagian besar siswa kelas I masih belum bisa membaca, jadi mereka kesulitan membaca teks yang ada dalam cerita dan anak masih sedikit kesulitan mengingat alur cerita untuk menjawa soal dalam media. Untuk menghadapi kendala tersebut awalnya guru memotong-motong cerita dengan mempause jalannya cerita, membacakan ulang percakapan pada tokok, dan menceritakan ulang jalan cerita.

Multimedia interaktif ceria ini telah menjalani serangkaian validasi dan uji coba. Dalam penelitian ini media dinilai "valid" oleh semua validator dalam angket yang disajikan pada validator. Jalan cerita sudah sesuai tema kelas I.

Namun pemilihan tema agar dilakukan hati-hati dengan memilih tema yang dekat dengan kehidupan sehari-hari siswa, hal ini sesuai dengan pendapat Dilek (dalam Parwati, 2010: 342). 
Berdasarkan tema yang telah dipilih yang dibahas dalam CD Interaktif adalah cerita tentang kehidupan dalam keluarga sebagai seorang anak, meliputi kedudukan dalam keluarga, berbagi dalam keluarga: operasi penjumlahan dan pengurangan sampai 20, adab dalam keluarga, kewajiban dalam keluarga, dan hak dalam keluarga.

Dengan menanpilkan cerita sesuai kehidupan sehari-hari mereka diharapkan siswa lebih mudah menyerap materi dan lebih luar referensi tentang soal-soal, tidak hanya dalam buku teks.

\section{SIMPULAN}

Berdasarkan hasil penelitian dan pembahasan, dapat disimpulkan bahwa pengembangan multimedia ini dilakukan melalui tiga tahap: a) studi pendahuluan (survey lapangan, need asessment dan studi (pustaka), b) pengembangan produk multimedia, validasi ahli, uji coba terbatas, c) pengujian melalui kegiatan penelitian eksperimen dari produk hipotetik pada kegiatan pembelajaran yang sebenarnya dilapangan.

Hasil penelitian pengembangan ini adalah menghasilkan media pembelajaran dalam bentuk multimedia interaktif ceria dikemas dalam CD Interaktif. Multimedia ini terbentuk dari berbagai komponen media dalam satu-kesatuan yang utuh. Multimedia ini berisi tentang cerita keluarga yang memberikan nilai kehidupan pada siswa. Terdapat pula latihan soal yang memperkuat pemahaman siswa pada materi. Cara menggunakan multimedia ini adalah dengan menggunakan perangkat komputer atau laptop, LCD dan proyektor, karena media yang berbentuk software dalam kepingan $\mathrm{CD}$.

Hasil penelitian ini menunjukkan hasil yang sesuai harapan, bahwa multimedia memiliki daya guna yang meliputi: a) produk multimedia dikembangkan dalam bentuk cerita anak dan latihan soal, b) kualitas produk multimedia interaktif ceria termasuk dalam kategori sangat baik, diketahui dari meningkatknya pengetahuan siswa terhadap materi tema keluargaku yang dapat dilihat dari perbedaan nilai pretest (sebelum menggunakan multimedia) dan nilai posttest (sesudah menggunakan multimedia), c) produk ini memiliki keunggulan dari media lainnya karena memiliki semua bentuk media mulai dari audio sampai visual, d) berdasarkan hasil analisis dari penilaian para ahli (ahli materi dan ahli media) dan uji coba terbatas dapat ditarik suatu hal yaitu bahwa multimedia interaktif ceria yang dikembangkan layak dan memiliki daya guna tinggi pada pembelajaran di kelas dan multimedia interaktif ini dapat dijadikan suatu pertimbangan khusus sebagai media pembelajaran tematik.

Beberapa saran yang bisa diajukan adalah penggunaan multimedia interaktif ceria akan lebih memiliki daya guna yang lebih tinggi jika siswa dapat menjalankan multimedia secara individu, untuk penelitian selanjutnya disarankan dalam video pada tulisan percakapan menggunakan huruf sesuai kelas I, yaitu huruf latin, dicantumkan pula peta konsep materi pada media dan animasi disesuaikan dengan anak-anak, perlu perluasan populasi dan sampel agar pengembangan menghasilkan produk lebih baik dan memiliki tingakt kevalidan lebih tinggi, dan disarankan semua kelas I SD menggunakan media pembelajaran, khususnya multimedia interaktif ceria. Sehingga menghidupkan suasana kelas yang akan menciptakan penyampaikan materi lebih konkrit dan motivasi belajar siswa dapat meningkat serta dapat meningkatkan kreativitas siswa.

\section{DAFTAR RUJUKAN}

Akbar, Sulthan. 2011. Pengembangan Multi media Interaktif Mata Pelajaran Ilmu Pengetahuan Alam Kelas V di SDN Merjosari 5 Malang. Skripsi tidak 
diterbitkan. Malang: Universi- tas Negeri Malang.

Anonim. 2006. Gambar Animasi. (Online). http://www.education.vic.gov.au/languages online/games/cartoon/index.htm, diakses tanggal 14 April 2014.

Anonim. 2014. Gambar Background. (Online). http://gambarkata.com/gambar-pemandanganindah-sedunia-berjenis-kartun.htm, diakses tanggal 14 April 2014.

Anonim. 2014. Suara Backsound. (Online). http://sourceforge.net/, diakses tanggal 14 April 2014.

Arifin, Zainal. 2012. Penelitian Pendidikan. Bandung: PT Remaja Rosdakarya.

Arikunto, Suharsimi. 2006. Prosedur Penelitian: Suatu Pendekatan Praktik. Jakarta: PT Rineka Cipta.

Arsyad, Azhar. 2009. Media Pembelajaran. Jakarta: Rajawali Pers.

BSNP. 2006. Panduan penyusunan kurikulum tingkat satuan pendidikan jenjang pendidikan dasar dan menengah. Jakarta: BSNP.

Hayati, Sri. 2013. Pengembangan Media Kartu Domino untuk Peningkatan Kemampuan Penjumlahan dan Pengurangan Bilangan Pecahan pada Siswa Kelas V SD. Skripsi tidak diterbitkan. Malang: Universitas Muhammadiyah Malang. Dari Digilib, (Online), (http//www.digilib.umm.ac.id), diakses $18 \quad$ Mei 2014.

Inovatif Berorientasi Konstruktivistik. Jakarta: Prestasi Pustaka Publiser

Majid, Abdul. 2014. Pembelajaran Tematik Terpadu. Bandung: PT Remaja Rosda karya.

Mulyasa. 2013. Pengembangan dan Implementasi Kurikulum 2013. Bandung: PT Remaja Rosdakarya.

Munadi, Yudhi. 2013. Media Pembelajaran. Jakarta: GP Press Group.
Musfiroh, Tadkiroatun. 2010. Cerita untuk Perkembangan Anak. Yogyakarta: Navila.

Parwati, Ni Nyoman, dkk. 2010. Pengembangan Perangkat Pembelajaran Matematika Berpendekatan Tematik untuk Meningkatkan Kompetensi Berpikir Kritis, Kreatif, dan Produktif pada Siswa SD. Jurnal Penelitian dan Pengembangan Pendidikan (JPPP), Lembaga Penelitian Universitas Pendidikan Ganesha, (Online), 4(3): 329-345, (http//www.lemlit undiksha.co.nr), diakses 20 Desember 2013.

Permendikbud. 2013. Standar Proses Pendidikan Dasar dan Menengah. Jakarta: Depdiknas.

PP RI Nomor 19. 2005. Standar Nasional Pendidikan. Jakarta: Depdiknas.

PP RI Nomor 32. 2013. Standar Nasional Pendidikan. Jakarta: Depdiknas.

Riani, Sri. 2013. Pengembangan Media Pembelajaran Berbasis Multimedia Interaktif Untuk Meningkatkan Pemahaman Materi Bioteknologi Modern Pada Kelas VII SMA. Skripsi tidak diterbitkan. Malang: Universitas Muhammadiyah Malang. Dari Digilib, (Online), (http//www.digilib.umm.ac.id), diakses 18 Mei 2014.

Rusman. 2012. Model-model Pembelajaran: Mengembangkan Profesionalisme Guru. Jakarta: Rajawali Pers

Setyosari, Punaji. 2010. Metode Penelitian Pendidikan dan Pengembangan. Jakarta: Kencana.

Sudaryono, dkk. 2013: Pengembangan Instrumen Penelitian Pendidikan. Yogyakarta: Graha Ilmu

Sudjana, Nana dan Rivai, Ahmad. 2013. Media Pengajaran. Bandung: Sinar Baru Algensindo. 
Sugiyono. 2008. Metode Penelitian Pendidikan (Pendekatan Kuantitatif, Kualitatif, dan $R \& D)$. Bandung: Alfabeta.

Sukardi. 2013. Metodologi Penelitian Pendidikan (Kompetensi dan Praktiknya). Jakarta: PT Bumi Aksara.

Sukmadinata, Nana Syaodih. 2007. Metode Penelitian Pendidikan. Bandung: PT Remaja Rosdakarya.

Susilana, Rudi. 2007. Media Pembelajaran. Bandung: CV. Wacana Prima.

Suwindra, I Nyoman P, dkk. 2009. Peningkatan Kompetensi Fisika Siswa melalui Pembelajaran Berbasis Berbantuan Multimedia Interaktif di SMA Negeri Busungbiu. Jurnal Penelitian dan Pengembangan Pendidikan (JPPP), Lembaga Penelitian Universitas Pendidikan Ganesha, (Online), 4(3), (http//www.lemlit-undiksha.co.nr), diakses 20 Desember 2013.

Suwindra, I Nyoman P, dkk. 2010. Pengembangan Modul Software Multimedia Interaktif untuk Meningkatkan Pemahaman Konsep dan Hasil Belajar Fisika Siswa SMA. Jurnal Penelitian dan Pengembangan Pendidikan (JPPP), Lembaga Penelitian Universitas Pendidikan Ganesha, (Online), 4(3) 282-299, (http//www.lemlit-undiksha.co.nr), diakses 20 Desember 2013.

Suyanto, M. 2006. Multimedia Alat untuk Meningkatkan Keunggulan Mutu Bersaing. Yogyakarta: ANDI.

Trianto. 2011. Model-model Pembelajaran UU Nomor 20. 2003. Standart Pendidikan Nasional. Jakarta: Depdiknas. . 2012. Mengembangkan Model Pembelajaran Tematik. Jakarta: Prestasi Pustaka Publiser. 